\title{
Clinical and radiological outcomes of denosumab and teriparatide treatment in elderly patients with osteoporotic spinal compression fracture without vertebroplasty
}

\author{
Joo Young Jung, Byoung Hun Lee, Jong Young Lee, Hong Jun Jeon, Byung Moon Cho, Su Yeon Kim, Se Hyuck Park \\ Department of Neurosurgery, Kangdong Sacred Heart Hospital, Hallym University College of Medicine, Seoul, Korea
}

Objective: Vertebroplasty is a common treatment for osteoporotic spinal compression fractures, but it poses complication risk. Therefore, we investigated the clinical and radiological outcomes of conservative treatment using a combination of denosumab and teriparatide.

Methods: This study included 86 patients aged 75 or older who were diagnosed with osteoporotic spinal compression fracture from January 2011 to April 2021. The patients were then categorized into those who received denosumab and teriparatide combination treatment without vertebroplasty(group A) and those who received bisphosphonate treatment and underwent vertebroplasty (group B). Several parameters were analyzed: age, sex, underlying diseases, BMI, hospital stay, the time of ambulation start, BMD, VAS score, compression ratio, regional Cobb angle, and local kyphotic angle.

Results: As compared to group A, group B showed a relatively shorter hospital stay and time until starting ambulation, but without statistical significance. The VAS scores measured at the time of injury, post-treatment, 3months post-injury, and 1year post-injury did not show statistically significant differences between the groups. In contrast, the mean BMD measured at the time of injury and 1year post-injury demonstrated statistically significant improvements in group A compared to group B. The differences in the compression ratio, regional Cobb angle, and local kyphotic angle measured at the time of injury and 1year post-injury were not statistically significant.

Conclusion: Combination treatment without vertebroplasty did not show significant differences in either clinical or radiologic results compared to vertebroplasty cases. Therefore, denosumab and teriparatide combination treatment could be considered as an alternative option for osteoporotic spinal compression fracture patients.

Keywords: Osteoporosis; Vertebral compression fracture; Vertebroplasty; Elderly patients; Bone density

\section{Introduction}

Osteoporosis is a widespread skeletal system disease, in which fractures easily occur due to low bone mass and structural aging, causing chronic back pain, spinal deformity, and fractures. Particularly,

Received: June 17, 2021

Revised: July 29, 2021

Accepted: August 3, 2021

Corresponding Author: Byoung Hun Lee, MD

Department of Neurosurgery, Kangdong Sacred Heart Hospital, Hallym

University College of Medicine, 150 Seongan-ro, Gangdong-gu, Seoul

05355, Korea

Tel: +82-2-2224-2493; Fax: +82-2-488-0114;

E-mail: saintnom@hanmail.net when accompanied by osteoporosis, spinal compression fractures can result from even a mild trauma or without any noticeable trauma, which is known to occur in $25 \%$ of all females over the age of 70 and $50 \%$ of all females over the age of 80 [1-3]. In the past, osteoporotic spinal compression fractures were thought to recover spontaneously without specific complications; however, with the recent increasing aging population and more osteoporosis-focused studies, these fractures are now reported to have physical, functional, and psychological sequelae, as well as cause serious complications, such as reduced quality of life and increased mortality, suggesting the need for an active therapeutic approach alongside osteoporosis treatment $[1,4,5]$.

Treatment for osteoporosis has become widespread following 
the discovery of estrogen and calcium administration in the early 1980s, wherein oral administrations became available after the late 1980s as the efficacy of additional drugs, such as bisphosphonate, calcitonin, and parathyroid hormone $(\mathrm{PTH})$, was uncovered $[6,7]$. Teriparatide and denosumab have been reported to be effective in osteoporosis treatment and prevention, leading to their active use in clinical settings $[8,9]$.

Vertebroplasty, conversely, is frequently performed for rapid pain reduction and earlier recovery of ambulation in spinal compression fracture patients with osteoporosis; however, follow-up reports have indicated that the artificially strengthened vertebral body causes injuries in the adjacent vertebral body [10-12]. As such, the authors investigate whether an active conservative treatment using denosumab and teriparatide combination alone could be used to improve the clinical and radiologic outcomes in elderly osteoporotic spinal fracture patients who are at risk of for vertebroplasty complications.

\section{Material and Method}

\section{Study design and patient selection}

A retrospective review was conducted with 86 patients aged 75 or older who were diagnosed with osteoporotic spinal compression fractures of the thoracic and lumbar spine and with a bone mineral density (BMD) of -3.0 or higher, between January 2011 and April 2021. Meanwhile, those with no follow-up for more than one year, have Kummell disease, or have diseases requiring surgery for neurological abnormalities were excluded. Exactly 41 subjects were included in group A (patients who received denosumab and teri- paratide combination without vertebroplasty), and 45 subjects were included in group B (patients treated with bisphosphonate with vertebroplasty) for comparison. denosumab and teriparatide both were started at the same time and maintained over 1 year in group A. In this study, alendronate and risedronate were used as bisphosphonate therapy in group B. All patients took analgesic and calcium preparations, as well as started ambulation early with braces. As this study was conducted as a retrospective study with chart review in the hospital, it received no IRB.

\section{Outcome evaluation}

Assessments were conducted based on the age, sex, body mass index (BMI), duration of hospital stay, the time point at which they started ambulation(we recommended after 2 or 3 days of bed rest with braces in both groups), BMD, smoking habits, hypertension, diabetes, history of stroke, visual analogue scale (VAS), compression ratio, regional Cobb angle, and local kyphotic angle. BMD was calculated with the average value of L1 to L4.

The compression ratio was calculated by setting the anterior height average of the adjacent upper and lower vertebrae as the estimated vertebral height, subtracting the current vertebral body height from the estimated vertebral body height, dividing the result by the estimated vertebral body height, and then finally converting the quotient into a percentage. For the regional Cobb angle, the acute angle between the upper and lower vertebrae of the fractured vertebra was measured. For the local kyphotic angle, the acute angle between the upper and lower edges of the fractured vertebral body was measured (Fig. 1).

Additionally, the values measured at the time of injury were used
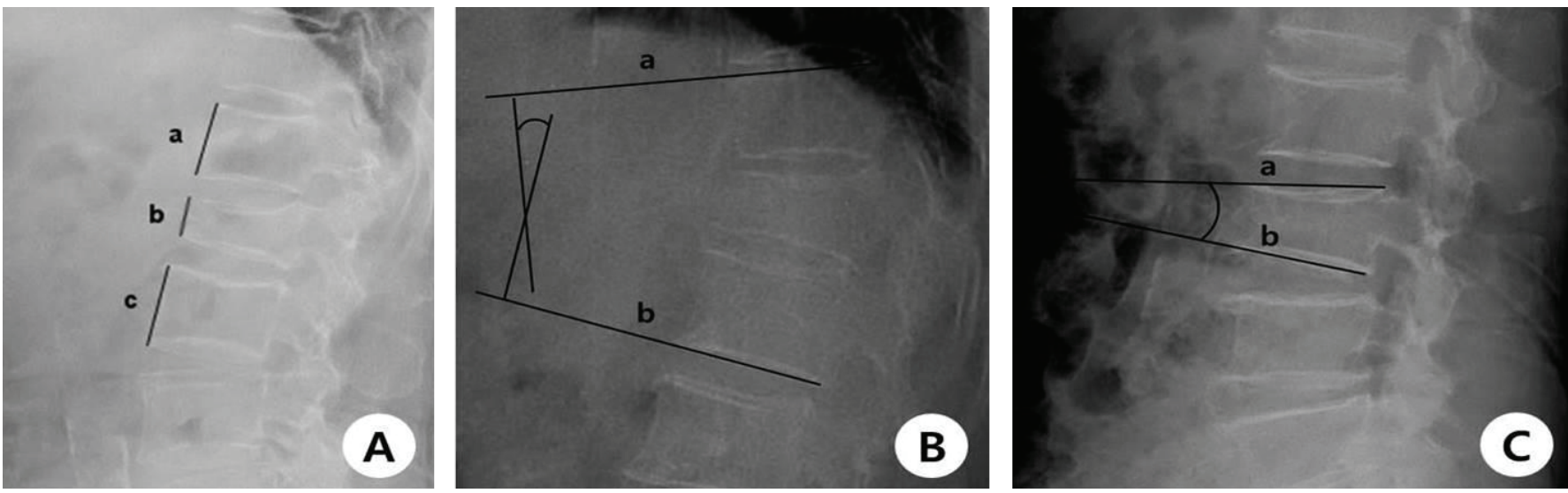

Fig. 1. (A) Compression ratio measurement using the following formula. Compression ratio $=\{[(a+c) / 2-b] /(a+c) / 2\} \times 100 \%$. $a: A n t e r i o r$ vertebral height of the upper vertebra; $b$ : anterior vertebral height of the fracture level; $c$ : anterior vertebral height of the lower vertebra. (B) Regional Cobb angle measurement using the following formula. Regional Cobb angle=acute angle measured between a and b. a: Superior vertebral line of the upper vertebra; $b$ : inferior vertebral line of the lower vertebra. (C) Local kyphotic angle measurement using the following formula. Local kyphotic angle=acute angle measured between a and b. a: Superior vertebral line of the fracture level; $b$ : inferior vertebral line of the fracture level. 
as the baseline for assessment, and the improvement in the VAS scores was re-evaluated by conducting follow-ups at the time of posttreatment, 3 months and one year post-injury. At 1-year follow-up, the changes in the compression ratio, regional Cobb angle, and local kyphotic angle were re-evaluated.

\section{Statistical analysis}

IBM SPSS ver. 26.0 (IBM Corp., Armonk, NY, USA) was used for statistical analysis. The chi-square test and the t-test were used for testing, and statistical significance was defined by the P-value of $<0.05$.

\section{Results}

\section{Demographics of patients}

Group A consisted of 3 males (7.3\%) and 38 females (92.7\%), whereas group B consisted of 5 males (11.1\%) and 40 females (88.9\%). The mean age was $82.12 \pm 5.04$ years old ( 75 to 95 years old) at the time of injury, with a mean age of $81.07 \pm 4.92$ years old
( 75 to 91 years old) for group A and $83.07 \pm 5.02$ years old ( 75 to 95 years old) for group $B$. The BMI was found to be normal with a BMI of $22.14 \pm 3.55 \mathrm{~kg} / \mathrm{m}^{2}$, wherein a mean BMI of $22.73 \pm 3.95$ $\mathrm{kg} / \mathrm{m}^{2}$ was found for group A and $21.54 \pm 3.02 \mathrm{~kg} / \mathrm{m}^{2}$ for group B. Furthermore, the mean BMD was $-3.56 \pm 0.43$, with a finding of $-3.51 \pm 0.42$ for group $A$ and $-3.62 \pm 0.44$ for group B. Regarding the accompanying underlying diseases, 27 patients $(65.9 \%)$ had hypertension, 14 patients $(34.1 \%)$ had diabetes, $6(14.6 \%)$ patients had stroke, 3 patients $(7.3 \%)$ had a history of smoking and 4 patients $(9.8 \%)$ had a previous vertebroplasty or balloon kyphosis in group A. Meanwhile, 24 patients (53.3\%) had hypertension, 17 patients $(37.8 \%)$ had diabetes, 5 patients $(11.1 \%)$ had stroke, 4 patients $(8.9 \%)$ had a history of smoking and 7 patients $(15.6 \%)$ had a previous vertebroplasty or balloon kyphosis in group B (Table 1).

\section{Level of vertebral compression fracture}

Compression fracture sites were observed from the 4th thoracic to the 4th lumbar vertebrae. More specifically, there were 17 thoracic

Table 1. Demographic and clinical characteristics of the patients

\begin{tabular}{|c|c|c|c|c|}
\hline Characteristic & Group A $(n=41)$ & Group B $(n=45)$ & Total $(n=86)$ & P-value \\
\hline Sex & & & & - \\
\hline Male & $3(7.3)$ & $5(11.1)$ & $8(9.3)$ & \\
\hline Female & 38 (92.7) & 40 (88.9) & 78 (90.7) & \\
\hline Age (yr) & $81.07 \pm 4.92$ & $83.07 \pm 5.02$ & $82.12 \pm 5.04$ & 0.141 \\
\hline Body mass index $\left(\mathrm{kg} / \mathrm{m}^{2}\right)$ & $22.73 \pm 3.95$ & $21.54 \pm 3.02$ & $22.14 \pm 3.55$ & 0.125 \\
\hline Bone mineral density & $-3.51 \pm 0.42$ & $-3.62 \pm 0.44$ & $-3.56 \pm 0.43$ & 0.078 \\
\hline Underlying disease & & & & - \\
\hline Hypertension & $27(65.9)$ & $24(53.3)$ & 53 (61.6) & \\
\hline Diabetes & $14(34.1)$ & 17 (37.8) & 31 (36.0) & \\
\hline Stroke history & $6(14.6)$ & $5(11.1)$ & $11(12.8)$ & \\
\hline Smoking history & $3(7.3)$ & $4(8.9)$ & $7(8.1)$ & \\
\hline Previous vertebroplasty or kyphoplasty history & $4(9.8)$ & $7(15.6)$ & $11(12.8)$ & \\
\hline Level of vertebral compression fracture & & & & - \\
\hline $\mathrm{T} 4$ & $1(2.4)$ & 0 & $1(1.2)$ & \\
\hline T5 & 0 & $1(2.2)$ & $1(1.2)$ & \\
\hline T8 & $2(4.9)$ & $0(0)$ & $2(2.3)$ & \\
\hline T9 & $1(2.4)$ & $2(4.4)$ & $3(3.5)$ & \\
\hline T10 & $1(2.4)$ & 0 & $1(1.2)$ & \\
\hline $\mathrm{T} 11$ & $2(4.9)$ & $2(4.4)$ & $4(4.7)$ & \\
\hline $\mathrm{T} 12$ & $10(24.4)$ & $9(20.0)$ & $19(22.1)$ & \\
\hline L1 & $13(31.7)$ & $18(40.0)$ & $31(36.1)$ & \\
\hline $\mathrm{L} 2$ & $7(17.1)$ & $11(24.4)$ & $18(20.9)$ & \\
\hline L3 & $3(7.3)$ & $2(4.4)$ & $5(5.8)$ & \\
\hline L4 & $1(2.4)$ & 0 & $1(1.2)$ & \\
\hline
\end{tabular}

Values are presented as number (\%) or mean \pm standard deviation.

Group A, denosumab+teriparatide without vertebroplasty; group B, bisphosphonate with vertebroplasty. 
(41.5\%) and 24 lumbar cases (58.5\%) in group A, while there were 14 thoracic (31.1\%) and 31 lumbar cases $(68.9 \%)$ in group B. In both groups, the cases involving the first lumbar vertebrae were accounted the most, with 13 cases (31.7\%) in group A and 18 cases (40.0\%) in group B (Fig. 2).

\section{Comparisons of clinical outcomes}

The mean duration of hospital stays and mean duration required to start ambulation was $12.30 \pm 8.56$ days and $7.52 \pm 4.39$ days in group $\mathrm{A}$, respectively, while it was $11.32 \pm 8.64$ days and $7.32 \pm 4.42$ days in group $B$, respectively. Although both values were shorter for group $B$ as compared to group $A$, there was no statistical significance. Meanwhile, the VAS scores for group A were $7.62 \pm 0.78,5.34 \pm 0.82,3.14 \pm 0.76$, and $1.98 \pm 0.79$ taken immediately after injury, posttreatment, at 3 months, and at one year post-injury, respectively, whereas the VAS scores in group B were $7.82 \pm 0.59,4.65 \pm 0.74,2.60 \pm 0.75$, and $1.96 \pm 0.70$, respectively. Both groups showed improvement but without statistically significant differences (Table 2).

\section{Comparison of BMD}

The bone density immediately after and one year after the injury was $-3.51 \pm 0.42$ and $-3.11 \pm 0.29$ for group A, respectively. Meanwhile, these values were noted to be $-3.62 \pm 0.44$ and $-3.34 \pm 0.32$ for group B, respectively. The improvement in mean BMD was statistically and significantly greater in group A, who were treated with denosumab and teriparatide combination, compared to that of group B (Table 3).

\section{Comparisons of radiologic outcomes}

In group $\mathrm{A}$, the compression ratio immediately and one year after

Table 2. Comparison of hospital days, days until ambulation, and visual analogue scale scores

\begin{tabular}{lccc}
\hline Variable & Group A & Group B & P-value \\
\hline Length of hospital stay (day) & $12.30 \pm 8.56$ & $11.32 \pm 8.64$ & 0.129 \\
Days until starting ambulation & $7.52 \pm 4.39$ & $7.32 \pm 4.42$ & 0.151 \\
Visual analogue scale & & & \\
$\quad$ Initial score & $7.62 \pm 0.78$ & $7.82 \pm 0.59$ & - \\
Posttreatment score & $5.34 \pm 0.82$ & $4.65 \pm 0.74$ & - \\
3-Month follow-up score & $3.14 \pm 0.76$ & $2.60 \pm 0.75$ & - \\
1-Year follow-up score & $1.98 \pm 0.79$ & $1.96 \pm 0.70$ & - \\
Change & $5.64 \pm 0.72$ & $5.86 \pm 0.76$ & 0.109 \\
\hline
\end{tabular}

Values are presented as mean \pm standard deviation.

Group A, denosumab+teriparatide without vertebroplasty; group B, bisphosphonate with vertebroplasty.

Table 3. Changes in bone mineral density

\begin{tabular}{lccc}
\hline Variable & Group A & Group B & P-value \\
\hline Initial BMD & $-3.51 \pm 0.42$ & $-3.62 \pm 0.44$ & - \\
1-Year follow-up BMD & $-3.11 \pm 0.29$ & $-3.34 \pm 0.32$ & - \\
Change & $0.40 \pm 0.13$ & $0.28 \pm 0.12$ & 0.022
\end{tabular}

Values are presented as mean \pm standard deviation.

Group A, denosumab+teriparatide without vertebroplasty; group B, bisphosphonate with vertebroplasty; BMD, bone mineral density.

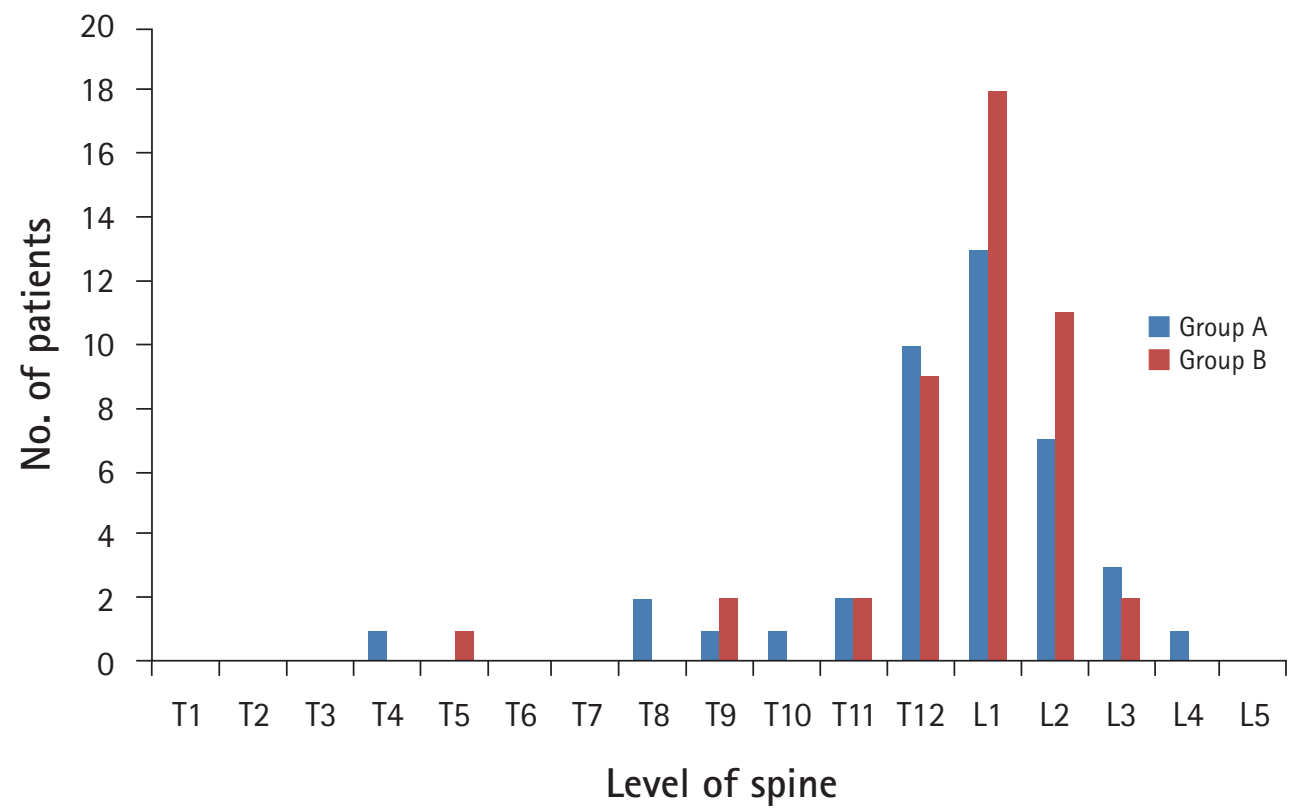

Fig. 2. Number of fractured vertebral bodies according to the specific spinal level. Group A, denosumab+teriparatide without vertebroplasty; group B, bisphosphonate with vertebroplasty. 
injury was $28.54 \% \pm 19.19 \%$ and $30.20 \% \pm 19.06 \%$, respectively, whereas in group B, it was $36.50 \% \pm 14.82 \%$ and $37.18 \% \pm 14.69 \%$, respectively. On the other hand, the regional Cobb angle immediately and one year after injury was $10.39^{\circ} \pm 9.80^{\circ}$ and $12.16^{\circ} \pm 8.87^{\circ}$ in group $\mathrm{A}$, respectively, while it was $15.25^{\circ} \pm 8.59^{\circ}$ and $15.94^{\circ}$ $\pm 9.51^{\circ}$ in group $B$, respectively. Additionally, the local kyphotic angle immediately and one year after the injury was $10.49^{\circ} \pm 8.07^{\circ}$ and $13.01^{\circ} \pm 8.31^{\circ}$ in group $A$, respectively, whereas it was $9.98^{\circ} \pm 6.24^{\circ}$ and $11.72^{\circ} \pm 7.17^{\circ}$ in group $B$, respectively. In comparison to group $\mathrm{A}$, the changes in compression ratio, regional Cobb angle, and local kyphotic angle in group B were smaller but had no statistically significant differences (Table 4).

\section{Discussion}

Spinal compression fractures due to osteoporosis can occur even with mild trauma and may also occur in daily life without any history of trauma, given that its incidence increases with age $[3,13-$ 15]. Moreover, based on recent research, it is known that every 1.0 decrease in the $\mathrm{T}$ score increases the risk of fractures by 2 -fold $[5,7,16]$. If, for example, the bone density decreases from $\mathrm{T}$ score of -3.0 to -4.0 , the risk of fractures increases from 8 times to 16 times $[5,16]$. Thus, in treating osteoporotic spinal compression fractures, osteoporosis treatment must also be accompanied. Active osteoporosis pharmacotherapy, such as teriparatide and denosumab, are known to be effective in osteoporosis treatment and prevention in addition to previously established medications, such as bisphosphonate, calcitonin, and PTH $[8,9]$. More specifically, according to several research, it is reported that an increase in lum-

Table 4. Changes in the compression ratio, regional Cobb angle and local kyphotic angle

\begin{tabular}{lccc}
\hline Variable & Group A & Group B & P-value \\
\hline $\begin{array}{l}\text { Compression ratio (\%) } \\
\quad \text { Initial ratio }\end{array}$ & $28.54 \pm 19.19$ & $36.50 \pm 14.82$ & - \\
$\quad$ 1-Year follow-up ratio & $30.20 \pm 19.06$ & $37.18 \pm 14.69$ & - \\
$\quad$ Change & $1.66 \pm 10.80$ & $0.68 \pm 8.85$ & 0.630 \\
Regional Cobb angle ( ${ }^{\circ}$ ) & & & \\
$\quad$ Initial angle & $10.39 \pm 9.80$ & $15.25 \pm 8.59$ & - \\
$\quad$ 1-Year follow-up angle & $12.16 \pm 8.87$ & $15.94 \pm 9.51$ & - \\
$\quad$ Change & $1.77 \pm 4.53$ & $0.68 \pm 4.98$ & 0.264 \\
Local kyphotic angle $\left(^{\circ}\right)$ & & & \\
$\quad$ Initial angle & $10.49 \pm 8.07$ & $9.98 \pm 6.24$ & - \\
$\quad$ 1-Year follow-up angle & $13.01 \pm 8.31$ & $11.72 \pm 7.17$ & - \\
$\quad$ Change & $2.51 \pm 3.43$ & $1.73 \pm 5.48$ & 0.385 \\
\hline
\end{tabular}

Values are presented as mean \pm standard deviation.

Group A, denosumab+teriparatide without vertebroplasty; group B, bisphosphonate with vertebroplasty. bar spine and femoral bone density is greater when receiving teriparatide and denosumab in combination as compared to their individual monotherapies $[17,18]$. As such, this study used denosumab and teriparatide combination as an active osteoporosis treatment for patients who did not receive vertebroplasty.

Based on previous studies, it has been known that osteoporotic spinal fractures have a relatively good prognosis, and acute pain disappears after 6 to 8 weeks, without causing severe physical or emotional impairment $[1,6]$. However, recent studies also reported that, once occurred, fracture results in physical and emotional disability in many patients, causing limitations in daily life due to persistent pain, loss of confidence, and depression even after recovery $[1,4,19]$. Furthermore, the progression of vertebral body compression may cause digestive disorders, such as early satiety and weight loss, due to decreased abdominal cavity volume following costal margin displacement towards the iliac crest, or due to hepatic function deterioration following pleural compression [1-3]. For these reasons, vertebroplasty is selectively being performed, as they have been reported to be excellent in acute pain control and early functional recovery as alternatives to conservative treatments, including bed rest, administration of anti-inflammatory drugs, walking with braces, and lifestyle training $[15,20]$. Despite this, there are many studies that still advocate for the use of conservative treatment due to the complications of the procedure itself, including bone cement outflow, vertebral body osteonecrosis, recompression, infection, and additional fractures to the adjacent vertebrae $[1,10,19,21]$.

In this study, the BMD measured immediately after and one year after injury was $-3.51 \pm 0.42$ and $-3.11 \pm 0.29$ in group $A$, respectively, after the combined use of denosumab and teriparatide. Meanwhile, for group B which received bisphosphonate treatment after vertebroplasty, these results were $-3.62 \pm 0.44$ and $-3.34 \pm$ 0.32 , respectively. In comparison, group A showed a greater and statistically significant mean $\mathrm{BMD}$ improvement, suggesting that greater effects in the improvement of osteoporosis with reduced risk for additional fractures can be expected from this combination treatment as compared to conventional bisphosphonate monotherapy.

In cases of an additional adjacent vertebral body fracture among osteoporotic spinal fracture complications, a study that performed conservative treatment reported that new vertebral body fractures occurred in $19.2 \%$ at 1-year follow-up [22].

However, when vertebroplasty was performed, Grados et al. [23] reported that new vertebral body fractures occurred in 13 out of 40 patients and in $52 \%$ of cases during a 48 -month follow-up period on average $[1,24]$. Furthermore, it was reported that artificially strengthened vertebral body increases the risk factor for adja- 
cent vertebral body fractures, which is caused by the shift in the normal load transmission. In other words, the strengthened vertebral body resulted in a loading pattern change during normal spinal load transmission, exerting a greater loading force on the adjacent vertebral body or on an area farther away and resulting in a compression fracture $[23,25]$. There was also no age or sex differences in the cases resulting in adjacent vertebral body fractures, which typically occurred within one year after initial vertebroplasty. Therefore, adjacent vertebral body fractures have been pointed out as a major issue in vertebroplasty $[10,12,26]$. In that regard, 6 cases of adjacent vertebral body fractures had been reported at 1-year follow-up after vertebroplasty in group B.

Despite the risks of such complications, vertebroplasty is known to reduce acute pain, resulting in quicker recovery of walking and increased activities in daily living in 90\% to $95 \%$ of osteoporotic compression fracture patients $[25,27]$. Thus, this procedure is still performed in many patients. In this study, it was confirmed that the mean duration of hospital stay and the time to recover walking were shortened in group B, who received bisphosphonate treatment along with vertebroplasty, as compared to that of group A, who only received conservative treatment including denosumab and teriparatide combination treatment; however, there were no statistically significant differences. This was likely because group A had started early walking with braces while concurrently receiving active pain management including pain killers and block whenever necessary.

Regarding pain control in this study, the VAS scores immediately, posttreatment, 3 months, and one year after injury was $7.62 \pm 0.78,5.34 \pm 0.82,3.14 \pm 0.76$, and $1.98 \pm 0.79$ for group A, and $7.82 \pm 0.59,4.65 \pm 0.74,2.60 \pm 0.75$, and $1.96 \pm 0.70$ for group $\mathrm{B}$, respectively, with both groups showing gradual improvement. As mentioned earlier, although group B showed relative benefit over group A in terms of acute phase pain improvement, there was no statistically significant difference in the mean improvement of pain when compared one year later.

Moreover, the differences in compression ratio, regional Cobb angle, and local kyphotic angle were compared immediately and one year after injury, but there were no statistically significant differences between the groups, with negligible levels of deterioration.

Although vertebroplasty can be helpful in controlling acute phase pain and improving early ambulation in osteoporotic compression fracture patients, it was shown that the combined use of denosumab and teriparatide can be selected to lower the risk of additional fractures and that the conservative treatment group did not show statistically significant differences from the vertebroplasty group. It was demonstrated that maintaining active conservative treatment without vertebroplasty could be an alternative therapeutic approach which could improve clinical symptoms, while reducing the risk of adjacent vertebral body fractures.

Despite these findings, the limitation of this study was that it was conducted as a retrospective study with a small sample of patients. Additionally, there could have been a bias arising from the difference in bisphosphonate monotherapy and denosumab and teriparatide combination therapy for osteoporosis. Thus, it would have been possible to compare the effects of vertebroplasty without bias if the combination therapy was also compared between the vertebroplasty group and the group without vertebroplasty. And long term follow-up study should be performed to compare in more detail further.

\section{Conclusion}

Although vertebroplasty is known to help reduce acute phase pain and improve time to early ambulation in the elderly with osteoporotic spinal fractures, a significant difference was not observed. Furthermore, it was confirmed that the mean BMD improvement was greater for the group receiving denosumab and teriparatide combination therapy as compared to the group receiving vertebroplasty, showing no significant differences in clinical and radiological outcomes. Therefore, in situations where there are risks of post-vertebroplasty complications in elderly spinal compression fracture patients with osteoporosis, active conservative treatment including injection treatment for osteoporosis can be considered as an alternative treatment.

\section{Conflicts of interest}

No potential conflict of interest relevant to this article was reported.

\section{ORCID}

Joo Young Jung, https://orcid.org/0000-0002-4817-4160 Byoung Hun Lee, https://orcid.org/0000-0003-1960-4106 Jong Young Lee, https://orcid.org/0000-0002-0883-841X Byung Moon Cho, https://orcid.org/0000-0001-9906-8125

\section{REFERENCES}

\author{
1. Koh YD, Kim JO, Kim RG, Kim DY, Kim NK, Kim DJ. Survival \\ analysis of conservative treatement in osteoporotic vertebral \\ fracture. J Korean Soc Spine Surg 2012;19:138-44. \\ 2. Schlaich C, Minne HW, Bruckner T, et al. Reduced pulmonary
}


function in patients with spinal osteoporotic fractures. Osteoporos Int 1998;8:261-7.

3. Leech JA, Dulberg C, Kellie S, Pattee L, Gay J. Relationship of lung function to severity of osteoporosis in women. Am Rev Respir Dis 1990; 141:68-71.

4. Suk SI, Lee CK, Kang HS, et al. Vertebral fracture in osteoporosis. J Korean Orthop Assoc 1993;28:980-7.

5. Melton LJ 3rd, Kan SH, Frye MA, Wahner HW, O'Fallon WM, Riggs BL. Epidemiology of vertebral fractures in women. Am J Epidemiol 1989;129:1000-11.

6. An KC. Nonoperative treatment of osteoporotic vertebral compression fracture. J Korean Fract Soc 2009;22:214-7.

7. Kim DH, Vaccaro AR. Osteoporotic compression fractures of the spine: current options and considerations for treatment. Spine J 2006;6:479-87.

8. Lyu H, Zhao SS, Yoshida K, et al. Comparison of teriparatide and denosumab in patients switching from long-term bisphosphonate use. J Clin Endocrinol Metab 2019; 104:5611-20.

9. Davis S, Simpson E, Hamilton J, et al. Denosumab, raloxifene, romosozumab and teriparatide to prevent osteoporotic fragility fractures: a systematic review and economic evaluation. Health Technol Assess 2020;24:1-314.

10. Park HG, Kim MH, Yoo MJ, et al. Complications after vertebroplasty of treatment for compression fracture with osteoporosis. J Korean Fract Soc 2003; 16:534-40.

11. Chun EO, Lee SG, Yoo CJ, Kim WK, Park CW, Lee U. Complication of the augmented vertebral body after percutaneous vertebroplasty in patients with osteoporotic compression fracture: hammer effect. Preliminary report. J Korean Neurosurg Soc 2003;34:565-9.

12. Rao RD, Singrakhia MD. Painful osteoporotic vertebral fracture. Pathogenesis, evaluation, and roles of vertebroplasty and kyphoplasty in its management. J Bone Joint Surg Am 2003;85:201022.

13. Cho CH, Park JT, Yun JK, Moon SK. Comparative analysis between male and female osteoporotic compression fractures in elderly patients. Korean J Neurotrauma 2013;9:131-4.

14. Ahn Y, Lee JH, Lee HY, Lee SH, Keem SH. Predictive factors for subsequent vertebral fracture after percutaneous vertebroplasty. J Neurosurg Spine 2008;9:129-36.
15. Pérez-Higueras A, Alvarez L, Rossi RE, Quiñones D, Al-Assir I. Percutaneous vertebroplasty: long-term clinical and radiological outcome. Neuroradiology 2002;44:950-4.

16. Kim WJ, Kang JW, Park KY, Park JG, Jung SH, Choy WS. Clinical outcome of conservative treatment for osteoporotic compression fractures in thoracolumbar junction.J Korean Soc Spine Surg 2006; 13:240-6.

17. Kim SW. Management of osteoporosis: who to treat, what to use, and for how long? Korean J Med 2013;85:364-73.

18. Tsai JN, Uihlein AV, Lee H, et al. Teriparatide and denosumab, alone or combined, in women with postmenopausal osteoporosis: the DATA study randomised trial. Lancet 2013;382:50-6.

19. Cooper C. The crippling consequences of fractures and their impact on quality of life. Am J Med 1997;103:12S-17S.

20. Barr JD, Barr MS, Lemley TJ, McCann RM. Percutaneous vertebroplasty for pain relief and spinal stabilization. Spine (Phila Pa 1976) 2000;25:923-8.

21. Kim SW, Chung YK. Long term follow-up of osteoporotic vertebral fractures according to the morphologic analysis of fracture pattern. J Korean Soc Spine Surg 2000;7:611-7.

22. Lindsay R, Burge RT, Strauss DM. One year outcomes and costs following a vertebral fracture. Osteoporos Int 2005;16:78-85.

23. Grados F, Depriester C, Cayrolle G, Hardy N, Deramond H, Fardellone P. Long-term observations of vertebral osteoporotic fractures treated by percutaneous vertebroplasty. Rheumatology (Oxford) 2000;39:1410-4.

24. Cyteval C, Sarrabère MP, Roux JO, et al. Acute osteoporotic vertebral collapse: open study on percutaneous injection of acrylic surgical cement in 20 patients. AJR Am J Roentgenol 1999;173: 1685-90.

25. Belkoff SM, Mathis JM, Erbe EM, Fenton DC. Biomechanical evaluation of a new bone cement for use in vertebroplasty. Spine (Phila Pa 1976) 2000;25:1061-4.

26. Ye HH, Cha JH, Cho CW, Kim YS, Kim DJ. The incidence of recurrent vertebral fracture after kyphoplasty or vertebroplasty. J Korean Neurotraumatol Soc 2008;4:84-8.

27. Park JW, Kong MH, Lee SK, Song KY, Kang DS. Improved quality of life after percutaneous vertebroplasty for osteoporotic vertebral body compression fractures in the elderly. J Korean Neurosurg Soc 2003;34:560-4. 